Subscriber access provided by University of East Anglia Library

\title{
Article
}

\section{Trade-induced atmospheric mercury deposition over China and implications for demand-side controls}

Long Chen, Jing Meng, Sai Liang, Haoran Zhang, Wei Zhang, Maodian Liu, Yindong Tong, Huanhuan Wang, Wei Wang, Xuejun Wang, and Jiong Shu

Environ. Sci. Technol., Just Accepted Manuscript • DOI: 10.1021/acs.est.7b04607 • Publication Date (Web): 12 Jan 2018

Downloaded from http://pubs.acs.org on January 29, 2018

\section{Just Accepted}

"Just Accepted" manuscripts have been peer-reviewed and accepted for publication. They are posted online prior to technical editing, formatting for publication and author proofing. The American Chemical Society provides "Just Accepted" as a free service to the research community to expedite the dissemination of scientific material as soon as possible after acceptance. "Just Accepted" manuscripts appear in full in PDF format accompanied by an HTML abstract. "Just Accepted" manuscripts have been fully peer reviewed, but should not be considered the official version of record. They are accessible to all readers and citable by the Digital Object Identifier (DOI®). "Just Accepted" is an optional service offered to authors. Therefore, the "Just Accepted" Web site may not include all articles that will be published in the journal. After a manuscript is technically edited and formatted, it will be removed from the "Just Accepted" Web site and published as an ASAP article. Note that technical editing may introduce minor changes to the manuscript text and/or graphics which could affect content, and all legal disclaimers and ethical guidelines that apply to the journal pertain. ACS cannot be held responsible for errors or consequences arising from the use of information contained in these "Just Accepted" manuscripts. 
1 Trade-induced atmospheric mercury deposition over China and implications for

2 demand-side controls

3

4 Long Chen, ${ }^{1,2}$ Jing Meng, ${ }^{3}$ Sai Liang, ${ }^{4}$ Haoran Zhang, ${ }^{5}$ Wei Zhang, ${ }^{6}$ Maodian Liu, ${ }^{5}$

5 Yindong Tong, ${ }^{7}$ Huanhuan Wang, ${ }^{5}$ Wei Wang, ${ }^{1,2}$ Xuejun Wang, ${ }^{*}, 5$ and Jiong Shu ${ }^{*}, 1,2$

6

$7{ }^{1}$ Key Laboratory of Geographic Information Science (Ministry of Education), East

8 China Normal University, Shanghai, 200241, China

$9{ }^{2}$ School of Geographic Sciences, East China Normal University, Shanghai, 200241, 10 China

$11{ }^{3}$ School of Environmental Sciences, University of East Anglia, Norwich NR4 7TJ, 12 UK

$13{ }^{4}$ State Key Joint Laboratory of Environmental Simulation and Pollution Control, 14 School of Environment, Beijing Normal University, Beijing, 100875, China

$15{ }^{5}$ Ministry of Education Laboratory of Earth Surface Process, College of Urban and 16 Environmental Sciences, Peking University, Beijing, 100871, China

$17{ }^{6}$ School of Environment and Natural Resources, Renmin University of China, Beijing, 18 100872, China

197 School of Environmental Science and Engineering, Tianjin University, Tianjin, 20300072 , China 


\section{Abstract}

Mercury $(\mathrm{Hg})$ is of global concern because of its adverse effects on humans and the environment. In addition to long-range atmospheric transport, $\mathrm{Hg}$ emissions can be geographically relocated through economic trade. Here, we investigate the effect of China's interregional trade on atmospheric $\mathrm{Hg}$ deposition over China, using an atmospheric transport model and multiregional input-output analysis. In general, total atmospheric $\mathrm{Hg}$ deposition over China is $408.8 \mathrm{Mg} \mathrm{yr}^{-1}$, and $32 \%$ of this is embodied in China's interregional trade, with the hotspots occurring over Gansu, Henan, Hebei, and Yunnan provinces. Interprovincial trade considerably redistributes atmospheric $\mathrm{Hg}$ deposition over China, with a range in deposition flux from $-104 \%$ to $+28 \%$. Developed regions, such as the Yangtze River Delta (Shanghai, Jiangsu, and Zhejiang) and Guangdong, avoid Hg deposition over their geographical boundaries, instead causing additional $\mathrm{Hg}$ deposition over developing provinces. Bilateral interaction among provinces is strong over some regions, suggesting a need for joint mitigation, such as the Jing-Jin-Ji region (Beijing, Tianjin, and Hebei) and the Yangtze River Delta. Transferring advanced technology from developed regions to their developing trade partners would be an effective measure to mitigate China's $\mathrm{Hg}$ pollution. Our findings are relevant to interprovincial efforts to reduce trans-boundary $\mathrm{Hg}$ pollution in China. 


\section{Introduction}

Mercury ( $\mathrm{Hg})$, known as a global neurotoxic pollutant, is released into the atmosphere from human activities, such as coal combustion, mining and commercial waste. ${ }^{1,2}$ The long atmospheric lifetime of elemental $\mathrm{Hg}^{0}$ results in its long-range atmospheric transport. Eventually, $\mathrm{Hg}^{0}$ is oxidized to divalent $\mathrm{Hg}^{\mathrm{II}}$, which is easily deposited in terrestrial and aquatic ecosystems. ${ }^{3,4}$ Methylation and bioaccumulation of $\mathrm{Hg}$ in food webs following deposition adversely affect humans and wildlife, especially prenatally exposed children. ${ }^{5-8}$ Atmospheric deposition is a critical process

following emissions, enhancing the risk of exposure to humans and wildlife. ${ }^{9}, 10$ Elevated $\mathrm{Hg}$ in the environment and its associated health impacts led to the launch of the Minamata Convention on Mercury ${ }^{11}$ to reduce global Hg emissions. Given $27 \%$ of the global anthropogenic $\mathrm{Hg}$ emissions to the atmosphere, ${ }^{12}$ Mainland China (termed as China) plays an important role in the global $\mathrm{Hg}$ cycle.

The Chinese government has already made substantial efforts to reduce atmospheric $\mathrm{Hg}$ emissions, mainly through measures related to improving energy efficiency and end-of-pipe controls. ${ }^{13-15}$ For instance, the use of air pollution control devices (APCDs) in coal-fired power plants, especially of electrostatic precipitators (ESP) and fabric filters (FF), flue gas desulfurization towers (FGD), and selective catalytic reduction (SCR), reached $100 \%, 92.1 \%$, and $83.2 \%$ in 2014 , respectively. ${ }^{16}$ In $\mathrm{Zn}$ smelters, the average $\mathrm{Hg}$ removal efficiency of APCDs reached 93\% in 2014. ${ }^{16}$ As a consequence, around $1002 \mathrm{Mg}$ of $\mathrm{Hg}$ from dominant emission sectors was removed in 2010 , while $73 \%$ of $\mathrm{Hg}$ from China's coal-fired power plants was 
removed in $2014 .{ }^{16}$ However, the effects of existing production-side controls have not achieved their desired goals, and $\mathrm{Hg}$ pollution is still a serious environmental issue in China. Therefore, new demand-side controls are being proposed, having the same importance as production-side controls. China has established standards for embedded Hg concentrations in domestically consumed goods, such as sphygmomanometers and fluorescent lamps. ${ }^{17}$ Meanwhile, the consumption of goods in specific sectors without embedded $\mathrm{Hg}$ can lead to upstream $\mathrm{Hg}$ emissions throughout the economic supply chains. Given this problem, new demand-side actions, ${ }^{18,}{ }^{19}$ such as implementing consumption taxes and transferring advanced technology and capital, are being proposed to mitigate the embodied $\mathrm{Hg}$.

Demand-side controls concern emissions embodied in the consumption of goods, which are involved in interregional trade. Trade redistributes such emissions, and geographically changes air pollution. ${ }^{20}$ For instance, the production of trade goods increases emissions locally, while reducing emissions in the consuming regions. Recently, $\mathrm{Hg}$ emissions in China relocated by interregional trade have been well-documented at different scales, such as city level, ${ }^{21,22}$ national level, ${ }^{19,23}$ and global level. ${ }^{18,24}$ In particular, a detailed and comprehensive view of the virtual atmospheric $\mathrm{Hg}$ emission network among Chinese provinces has been provided by Liang et al. ${ }^{19,23}$ The previous studies shed light on the virtual transport of $\mathrm{Hg}$ emissions via interregional trade. However, there still a gap in understanding how and where the redistributed emissions exert direct risks on humans and wildlife through atmospheric movement and deposition. 
In this study, we combine an emission inventory with a multiregional input-output model and an atmospheric transport model to simulate the atmospheric $\mathrm{Hg}$ deposition embodied in China's interregional trade and investigate how and where the redistributed emissions exert direct risks on humans and wildlife through atmospheric movement and deposition (SI S2). We classify contributions from final consumers to the deposition over receptors and assess the potential benefits of various demand-side measures (e.g., implementing consumption taxes and transferring advanced technology) for China. The main novelty of this study is to illustrate the effect of interregional trade and the benefits of relevant demand-side measures on humans and wildlife in deposited areas through atmospheric $\mathrm{Hg}$ deposition. Compared with previous studies, ${ }^{18,19,21-24}$ this study is more closely connected with health risks on humans and wildlife. Our results are relevant to interprovincial efforts to reduce trans-boundary $\mathrm{Hg}$ pollution and provide a scientific basis for the implementation of the Minamata Convention on Mercury within China.

\section{Materials and Methods}

\subsection{Production-based emission inventory}

$\mathrm{Hg}$ emissions from all sectors, including coal combustion, nonferrous metal smelting, cement production, and other production activities, are estimated by multiplying energy usage or product yields by their respective emission factors. Multiplying these values again by $\mathrm{Hg}$ speciation profiles, we estimate the emissions of $\mathrm{Hg}^{0}, \mathrm{Hg}^{\mathrm{II}}$ and particulate $\mathrm{Hg}^{\mathrm{P}}$. Wu et al. ${ }^{16}$ used a technology-based approach to 
compile the latest and comprehensive estimate of provincial emission factors and associated speciation profiles for all primary anthropogenic $\mathrm{Hg}$ sources. Emission factors for dominant sources were estimated based on the probability distribution of Hg concentration in fuel/raw materials and Hg removal via pretreatment and APCDs. We multiply the emission factors and speciation profiles by energy usage or product yield, collected from the China Energy Statistical Yearbook $2011^{25}$ and from relevant industrial statistical yearbooks, ${ }^{26-29}$ to estimate provincial and sectoral $\mathrm{Hg}$ emissions. In addition to primary anthropogenic $\mathrm{Hg}$ sources, its secondary emissions from the disposal of waste/byproducts (i.e., the use of Hg-added products) are identified (102 $\mathrm{Mg})^{18}$ and included in this study. In the atmospheric transport model, large coal-fired power plants, ${ }^{30}$ nonferrous metal smelter, ${ }^{31}$ cement plants, ${ }^{32}$ and iron and steel plants ${ }^{28}$ are treated as point sources and assigned to the corresponding model grid in terms of their productivity. The remaining emissions are regarded as nonpoint sources, which are distributed with high spatial resolution in terms of gridded population density. ${ }^{33} \mathrm{In}$ the multiregional input-output model, we use the emission inventory at a province-level resolution, including both point and nonpoint sources. The direct $\mathrm{Hg}$ emissions of various economic sectors in each province are given in SI Dataset S3.

\subsection{Multiregional Input-Output model}

The multiregional input-output (MRIO) model has been widely used for analyzing environmental issues in the context of increasing interregional trade. ${ }^{19,34-38}$ We use the MRIO table for China in 2010 from Liu et al., ${ }^{39}$ to quantify $\mathrm{Hg}$ emissions embodied in 
China's interregional trade. The MRIO table consists of the intermediate input/output for 30 economic sectors in 30 provinces (excluding Tibet, Taiwan, Hong Kong, and Macao), provincial final demand and international export, as well as provincial sectoral total monetary output. Moreover, we remove the column named "others" (regarded as the error of different statistics ${ }^{23,}{ }^{40}$ ) in the MRIO table. A brief introduction to the MRIO approach is given below, while more detailed descriptions of the approach can be found in previous studies. ${ }^{37,38,41}$ The MRIO approach assumes that

$$
\mathbf{X}=\mathbf{Z}+\mathbf{Y}=(\mathbf{I}-\mathbf{A})^{-1} \mathbf{Y},
$$

where $\mathbf{X}$ is a vector of provincial sectoral total monetary output; $\mathbf{Y}$ is a vector of the provincial sectoral final demand, including final consumption (F) (i.e., urban household consumption, rural household consumption, government consumption and investment) and international export (E); $\mathbf{Z}$ is the intermediate input/output matrix; and $\mathbf{A}$ represents the direct requirement coefficient matrix, whose element $\mathrm{A}_{i j}$ denotes the intermediate input from sector $i$ to produce a unit output for sector $j$. A can be used to characterize interregional economic interactions between sectors. $(\mathbf{I}-\mathbf{A})^{-1}$ is the Leontief inverse matrix, and $\mathbf{I}$ denotes the unity matrix.

By multiplying these values by the direct emission intensity (Eq. 2), we obtain province- and sector-specific consumption-based emissions (C) with the corresponding final consumption (F). We also obtain sector-specific consumption-based emissions (C) embodied in export to foreign countries, along with their corresponding international export (E). The results are shown in SI Dataset S3. 
$150 \mathbf{C}=\boldsymbol{\psi}(\mathbf{I}-\mathbf{A})^{-1} \mathbf{F}$,

151 where $\psi$ is a vector of direct emission intensity, including emission intensities of

152 total $\mathrm{Hg}$ and three $\mathrm{Hg}$ species, which defines the atmospheric $\mathrm{Hg}$ emissions per unit of 153 total output for each sector $(\mathrm{Mg}$ of $\mathrm{Hg} / \mathrm{RMB})$. Thus, $\psi \boldsymbol{\psi}$ reveals $\mathrm{Hg}$ inputs from raw materials and the efficiency of end-of-pipe $\mathrm{Hg}$ controls during production in each provincial sector. embodied in trade goods between trade partners, including emissions embodied in "international export" refers to China's exports to the rest of the world. For reference,

161 the locations of Chinese provinces are shown in SI Figure S1. Hg emissions embodied 162 in exports of goods from province $i$ to province $j$ (i.e., imports of goods in province $j$ 163 from province $i$ ) can be calculated from:

$164 \quad \mathrm{C}_{i j}=\boldsymbol{\psi}_{i}(\mathbf{I}-\mathbf{A})^{-1} \mathbf{F}_{j}$,

where $\psi_{i}$ denotes a vector with direct emission intensity for province $i$ but zero for all others, and $\mathbf{F}_{j}$ is a vector of final consumption for province $j$. Using this basic formula, we calculate EEE and EEI values for each province (SI S3). The difference between EEI and EEE represents the net emission transfer in interprovincial trade, equal to the difference between consumption-based and production-based emissions.

171 provinces, emissions avoided by imports (EAI) and emissions reduced by 
technological migration (ERM) are defined. EAI is defined as the additional emissions that a given province would have produced, if all imported goods consumed by the province had been made locally. It can be used to investigate the impact of interregional trade on atmospheric $\mathrm{Hg}$ deposition over China. Unlike previous studies, ${ }^{40,42}$ we assume that the production of the same goods releases different amounts of $\mathrm{Hg}$ among provinces mainly due to the difference of technologies. The total emissions avoided by imports for province $i$ can simply be expressed as:

$$
\mathrm{EAI}_{i}=\sum \mathrm{C}_{i j} \cdot \frac{\psi_{i}}{\psi_{j}}
$$

In this study, ERM is defined as the reduced EEI for a given province, if the province transfers a smaller $\psi$ to its trade partners. It is assumed to represent the impact on atmospheric $\mathrm{Hg}$ deposition over China of transferring advanced technology from developed provinces to their trade partners. The reduced emissions embodied in imports of province $i$ from province $j$ can simply be expressed as:

$\mathrm{ERM}_{i j}=\mathrm{C}_{i j} \cdot\left\{\begin{array}{cc}1-\frac{\psi_{i}}{\psi_{j}} & \psi_{i}<\psi_{j} \\ 0 & \psi_{i} \geq \psi_{j}\end{array}\right.$

The detailed calculation of EAI and ERM are outlined in SI S3.

\subsection{Atmospheric chemical transport model}

We simulate the atmospheric $\mathrm{Hg}$ deposition embodied in interregional trade over China using the GEOS-Chem chemical transport model (version 9-02; http://geos-chem.org). The model is a global 3-D atmospheric model, coupled to a 
193 2-D surface slab ocean and a 2-D soil reservoir. ${ }^{43,44}$ The model is driven by the

194 GEOS-5 assimilated meteorological fields, developed by the NASA Global Modeling 195 and Assimilation Office (GMAO). We implement a nested-grid capability with high 196 resolution over China within the GEOS-Chem model, based on the methods in Zhang 197 et al. ${ }^{45}$ and Wang et al. ${ }^{46}$ The nested model has $1 / 2^{\circ} \times 2 / 3^{\circ}$ horizontal resolution, and 19847 vertical levels from the surface to $0.01 \mathrm{hPa}$. Three $\mathrm{Hg}$ species (i.e., $\mathrm{Hg}^{0}, \mathrm{Hg}^{\mathrm{II}}$, and $199 \mathrm{Hg}^{\mathrm{P}}$ ) are tracked with oxidation of $\mathrm{Hg}^{0}$ by $\mathrm{Br}$ atoms, photoreduction of $\mathrm{Hg}^{\mathrm{II}}$ in 200 droplets and gas-particle partitioning between $\mathrm{Hg}^{\mathrm{II}}$ and $\mathrm{Hg}^{\mathrm{P}} \cdot{ }^{43,47}$ We first conduct a 201 global $4^{\circ} \times 4.5^{\circ}$ simulation for the period 2008-2010 to determine lateral boundary 202 conditions for the nested model every 3 hours. Then we run the nested model for the 203 study year (2010), with an initial spin-up time spanning the last three months of 2009. 204 The global simulation is driven by the emission inventory of China and the 205 AMAP/UNEP (Arctic Monitoring and Assessment Programme/United Nations 206 Environment Programme) global anthropogenic emission inventory out of China. ${ }^{12}$ 207 The outputs are archived monthly, and used to calculate average atmospheric $\mathrm{Hg}$ 208 deposition for the various regions of interest. We first conduct simulations with 209 production-based emissions to evaluate the nested model's performance against a 210 series of observations from published literature. Details of the evaluation are given in 211 SI S4.

212 To identify contributions from each source, an explicit tagging technique is added 213 to the GEOS-Chem model, adopted from previous applications used to estimate 214 source-receptor relationships for $\mathrm{SO}_{2}, \mathrm{BC}$ and $\mathrm{PM}_{2.5}$ on continental and national 
215 scales. $^{34,48,49}$ Throughout this tagging approach, $\mathrm{Hg}$ is emitted from a series of

216 sources, is tagged and explicitly tracked using additional model variables in a single

217 model simulation. Breaking from traditional sensitivity approaches, this method

218 avoids modifying $\mathrm{Hg}$ emissions to maintain local integration of atmosphere and

219 climate. This method also avoids the assumption that the response to perturbations is

220 linear and saves computational costs by using a sensitivity approach.

\section{Results and Discussion}

223

\subsection{Atmospheric Hg emissions and consequent deposition embodied in trade}

China releases a total of $641.7 \mathrm{Mg}$ of $\mathrm{Hg}$ to the atmosphere in 2010, of which 24.2 $\mathrm{Mg}$ of $\mathrm{Hg}$ is from residential coal combustion and use of $\mathrm{Hg}$-added products, which is not involved in the economic activities. Thus, $617.5 \mathrm{Mg}$ of $\mathrm{Hg}$ is included in the MRIO analysis herein. For consumption-based emissions, $81.9 \%(505.5 \mathrm{Mg})$ of $\mathrm{Hg}$ is induced by domestic consumption, while the remaining amount is induced by foreign consumption. A comparison of production-based and consumption-based $\mathrm{Hg}$ emissions in 2010 for 30 Chinese provinces is shown in Figure 1A. The different distribution patterns between the production-based and consumption-based emissions observed in 2010 are similar to the results for 2007 presented in Liang et al. ${ }^{19}$ Some developing provinces, such as Henan, Shandong, Gansu, Yunnan, Hebei and Inner Mongolia, which mainly produce primary and semi-manufactured products (e.g., fossil fuels, metals, and nonmetallic mineral products), are located upstream of the Chinese economic supply chains. These provinces have larger production-based 
emissions than consumption-based emissions. For instance, Henan ranks first, with a total of production-based emissions of $65.8 \mathrm{Mg}$, followed by Shandong (55.3 Mg), Gansu (45.4 Mg), and Yunnan (43.7 Mg). In contrast, developed provinces, which are located downstream of the Chinese economic supply chains, such as Beijing, Tianjin, Shanghai, Jiangsu, Zhejiang, and Guangdong, have larger consumption-based emissions. The difference between production-based and consumption-based emissions reflects the transfer of emissions via trade. Figures $1 \mathrm{~B}$ and $1 \mathrm{C}$ illustrate the emissions embodied in exports and imports of goods and services for each province. It shows that eleven provinces are net embodied $\mathrm{Hg}$ importers, while the other provinces are net embodied exporters. Among the provinces, the largest importer is Zhejiang (9.9 Mg), and the largest exporter is Henan (30.1 Mg). Similar to previous studies, ${ }^{19}$, ${ }^{23}$ we also find that emissions flow from the southeast coast to inland regions as a result of interprovincial trade.

The total atmospheric Hg deposition over China simulated by the model is 408.8 $\mathrm{Mg} \mathrm{yr}^{-1}$, with $59 \%$ of this amount reflecting China's anthropogenic sources (SI Dataset S8, Figure S3) and the remaining being from natural sources or foreign anthropogenic sources. Thus, the $\mathrm{Hg}$ deposition related to China's anthropogenic sources accounts for $60 \%-90 \%$ of the total $\mathrm{Hg}$ deposition over most of China (Figure 2A). China's anthropogenic sources also contribute to downwind deposition over the Northwest Pacific Ocean and other East Asian countries. However, this deposition decreases rapidly a certain distance away from mainland hotspots. Of the total deposition over China, $48 \%$ is induced by domestic consumption, including 
interprovincial trade, while $11 \%$ is induced by foreign consumption via international export. This indicates the importance of domestic consumption in determining atmospheric Hg deposition over China. Furthermore, 32\% of the total deposition over China is embodied in exports or imports of goods among China's trade partners (SI Dataset S8), with hotspots occurring in Gansu, Henan, Hebei and Yunnan (Figure 2B). Of the trade-induced deposition over China, the deposition embodied in interprovincial trade $\left(87.5 \mathrm{Mg} \mathrm{yr}^{-1}\right)$ is larger than the deposition embodied in international export (43.6 $\mathrm{Mg} \mathrm{yr}^{-1}$ ) (SI Dataset S8). The largest hotspot occurs over central provinces (e.g., Gansu, Henan, and Hebei) for interprovincial trade, but over southern provinces (e.g., Yunnan, and Guangdong) for international export (Figures 2C and 2D). The substantial embodied atmospheric $\mathrm{Hg}$ deposition reveals there is a profound influence of interregional trade and trans-boundary transport on atmospheric Hg pollution in China.

\subsection{Redistribution of atmospheric $\mathrm{Hg}$ deposition by trade}

Using EAI, we investigate the impact of China's interregional trade on the atmospheric $\mathrm{Hg}$ deposition over China, especially impacts of interprovincial trade. Figure 3 shows that interprovincial trade considerably redistributes atmospheric $\mathrm{Hg}$ deposition over China, with a range in deposition flux from $-104 \%$ to $+28 \%$. Atmospheric Hg deposition over most central and eastern provinces is enhanced, except over the Yangtze River Delta (i.e., Shanghai, Jiangsu, and Zhejiang), the Beijing-Tianjin region and the southeast coast, where $\mathrm{Hg}$ deposition is diminished 
281 (Figure 3A). In the case of southwestern and northwestern provinces, atmospheric $\mathrm{Hg}$ 282 deposition is diminished over Yunnan, Guizhou, Sichuan, Shaanxi, Ningxia and 283 Xinjiang, but considerably enhanced over Gansu. The provinces having reduced $\mathrm{Hg}$ 284 deposition show that a large decrease in deposition induced by their trade activities 285 can compensate for the increase induced by the trade activities of other provinces 286 (Figure 3B). Large EAIs for these provinces result in large reductions in deposition 287 over these provinces (SI Dataset S5). For developed regions (e.g., the Yangtze River 288 Delta and the Beijing-Tianjin region), large EEIs result in large EAIs. For developing 289 provinces (e.g., Yunnan, Guizhou, and Sichuan), small EEIs but less advanced production technology result in large EAIs (Figure 3B).

The pattern emerging in Figure 3B shows aggregated decreased groups along the diagonal, while increased groups away from the diagonal. The aggregated decreased groups along the diagonal indicate that all provinces could avoid $\mathrm{Hg}$ deposition over their geographic boundaries by importing goods. In the case of some provinces (e.g., Hebei, Zhejiang, and Gansu), their neighbors (e.g., Beijing, Shanghai, and Ningxia, respectively) could also avoid $\mathrm{Hg}$ deposition due to their imports of goods. The largest such decrease occurs between neighbors, Zhejiang and Shanghai $(-8.0 \%)$. The reduced deposition over their neighbors induced by their large EAIs could compensate for the increased deposition over their neighbors induced by their EEIs. However, in the case of remote receptors, the reduced deposition induced by EAIs of all provinces could not compensate for the increased deposition induced by their EEIs. In particular, the Yangtze River Delta and Guangdong both cause marked increases in 
$\mathrm{Hg}$ deposition over other provinces. Importing goods by developed regions of China could avoid large amounts of $\mathrm{Hg}$ deposition over their geographic boundaries, but cause substantially additional $\mathrm{Hg}$ deposition over developing provinces, which reveals a need for implementing demand-side measures in these developed provinces.

Figure $3 \mathrm{C}$ illustrates the variation related to trade-induced $\mathrm{Hg}$ deposition over the whole country from each source province and shows two opposite patterns. Importing goods by developed provinces, such as Beijing, Shanghai and Guangdong, causes additional $\mathrm{Hg}$ deposition over the whole country, and Guangdong ranks first with an increase of $1.3 \%$. Importing goods by developing provinces, such as Henan, Yunnan and Shaanxi, allows the whole country to avoid Hg deposition, and Yunnan ranks first with a decrease of $-1.5 \%$. Thus, in terms of trade-induced deposition, the whole country would benefit from cooperation between demand-side measures in developed provinces and end-of-pipe measures in developing provinces.

\subsection{Implications for demand-side $\mathrm{Hg}$ controls}

Mercury controls have been the goal of both national and global policymakers. ${ }^{12,}$

${ }^{50}$ In addition to production-side measures, the Chinese government is suggested to put demand-side $\mathrm{Hg}$ measures into action. Substantial embodied atmospheric $\mathrm{Hg}$ deposition and associated profound redistributions of the deposition by trade indicate there is a large potential for effective implementation of demand-side $\mathrm{Hg}$ controls to reduce $\mathrm{Hg}$ pollution in China. Given this potential, we classify the source contributions of atmospheric $\mathrm{Hg}$ deposition and investigate the effects under 
substitution of emission intensity. In this way, we assess the potential benefits of specific demand-side measures under consideration in China.

\subsubsection{Implications inferred from classification of source contributions}

By combining atmospheric movement and emission flows in trade, the source of atmospheric $\mathrm{Hg}$ deposition can be classified according to its on-site emission location and its final consumer of the relevant products. The classification of consumer sources is informative for judging the priority of cooperative $\mathrm{Hg}$ mitigation. We introduce changes in atmospheric $\mathrm{Hg}$ deposition in a receptor region resulting from a unit of final consumption in a source (in $\% /\left(\right.$ trillion $\left.\mathrm{RMB} \cdot \mathrm{yr}^{-1}\right)$ ), as an indicator for the classification of source contributions.

Figure 4A shows the emission flows in trade, while Figure 4B illustrates the classification of source contributions to receptors' atmospheric $\mathrm{Hg}$ deposition. The patterns in Figure 4A and 4B both show aggregated groups along the diagonal and row-like distribution of eminent contributions. When discussing atmospheric deposition, some southwestern provinces (e.g., Chongqing, Guizhou, and Yunnan) and northwestern provinces (e.g., Gansu, and Ningxia) show significant local influence, indicating local consumption and emissions, as well as a near-source regional deposition. Some groups, such as Gansu-to-Ningxia $\left(37.5 \% /\left(\right.\right.$ trillion $\left.\left.\mathrm{RMB} \cdot \mathrm{yr}^{-1}\right)\right)$, Gansu-to-Shaanxi $\quad\left(9.9 \% /\left(\right.\right.$ trillion $\left.\left.\quad \mathrm{RMB} \cdot \mathrm{yr}^{-1}\right)\right)$ and Guizhou-to-Chongqing $\left(8.3 \% /\left(\right.\right.$ trillion $\left.\left.\mathrm{RMB} \cdot \mathrm{yr}^{-1}\right)\right)$, have small values in Figure 4A, but large values in Figure 4B. This indicates the influence of atmospheric movement from upwind provinces to 
downwind provinces. Bilateral interaction among provinces is strong in some specific regions, such as within the Jing-Jin-Ji region (Beijing, Tianjin, and Hebei) and the Yangtze River Delta, because of their close geographical locations and frequent economic trade (Figure 4B). These regions require joint control measures. The final consumption of the Yangtze River Delta is the most effective driver for $\mathrm{Hg}$ deposition over most of China, making a contribution of $2.0 \% /\left(\right.$ trillion $\left.\mathrm{RMB} \cdot \mathrm{yr}^{-1}\right)$. In contrast, receptors, such as Tianjin, Shanghai, Sichuan, Inner Mongolia, Shaanxi and Qinghai, have similar local contributions and contributions from one other province to $\mathrm{Hg}$ deposition (i.e., in these cases: Hebei contributes to Tianjin, Zhejiang to Shanghai, Chongqing to Sichuan, Ningxia to Inner Mongolia, and Gansu to Shaanxi and Qinghai), indicating the need for interprovincial collaboration on $\mathrm{Hg}$ controls.

As a developing country undergoing rapid economic development, it is unrealistic to reduce the consumption of all goods and services in China. However, changing consumer behavior by shifting consumption of goods and services with large embodied $\mathrm{Hg}$ emissions to consumption of those that have lower embodied $\mathrm{Hg}$ emissions would be an effective way of reducing $\mathrm{Hg}$ deposition over China. A promising method would be to implement consumption taxes based on embodied $\mathrm{Hg}$ emissions. This would influence the consumption pattern of consumers, resulting in less embodied $\mathrm{Hg}$ consumption and lower $\mathrm{Hg}$ emissions, ${ }^{18}$ consequently, reducing atmospheric $\mathrm{Hg}$ deposition. Regional differentiation and collaboration in the implementation of consumption taxes would need to be considered, according to our results. In southwestern and northwestern provinces, measures taken in local regions 
may primarily benefit local environment. However, in northern and eastern provinces, measures taken in local regions will benefit the environment in both local and neighboring regions equally (e.g., Hebei-to-Tianjin and Zhejiang-to-Shanghai). The Yangtze River Delta, in particular, is a priority area, where demand-side measures would effectively benefit most of China.

\subsubsection{Implications inferred from hypothetical substitution of emission intensity}

Developed provinces, such as Beijing, Tianjin, Shanghai, Jiangsu, Zhejiang, and Guangdong, located downstream of the Chinese economic supply chains, would be responsible for the provinces with greater influence from their trade activities. Therefore, based on a hypothetical substitution of emission intensity, we introduce ERM to investigate the impact of a hypothetical transfer of advanced technology from developed provinces to their trade partners on atmospheric Hg deposition over China. Figure 5 illustrates the spatial distributions of reductions in atmospheric $\mathrm{Hg}$ deposition under such a transfer scheme for the six developed provinces. Though transferring advanced technology to trade partners, developed provinces would cause considerable reductions in atmospheric $\mathrm{Hg}$ deposition over China. However, the spatial distributions of these reductions are different among the six provinces. The measure from Beijing would cause reductions over the northern provinces, especially Hebei $(-3.3 \%)$ and the Beijing-Tianjin region $(-2.2 \%)$. The impact of the measure from Tianjin has a similar distribution to that of Beijing, but the reductions would be smaller. Measures from the Yangtze River Delta (i.e., Shanghai, Jiangsu, and Zhejiang) 
cause the most extensive reductions over China. In the case of Shanghai, the reduction hotspot is over the central and eastern provinces, such as Henan (-2.6\%) and Zhejiang $(-2.2 \%)$. In case of Jiangsu, the reduction hotspot is over the northwestern provinces, such as Gansu (-3.7\%). In addition to the northwestern provinces, the measure from Zhejiang also causes a reduction over the southwestern provinces. Unlike the Beijing-Tianjin region and the Yangtze River Delta, the measure from Guangdong could reduce $\mathrm{Hg}$ deposition mainly over the southwestern provinces, such as Yunnan $(-4.8 \%)$. We also investigate the same measure for other provinces and find the reductions of deposition induced by developed provinces are larger than developing provinces (SI S5).

As the developed regions in China, the Beijing-Tianjin region, the Yangtze River Delta and the Pearl River Delta appear to contribute large additional loads to $\mathrm{Hg}$ deposition over developing provinces, and they are gave a priority need of implementing demand-side measures (Figure 3). Furthermore, they have more advanced technology than developing provinces. If they transferred advanced technology to their trade partners, then atmospheric $\mathrm{Hg}$ deposition over these developing regions would be considerably reduced. Therefore, importing goods coupled with transfer of advanced technology in developed regions would be an effective measure to mitigate China's $\mathrm{Hg}$ pollution. Given the different spatial distributions of such reductions, we need to pay attention to measures in different developed regions when mitigating $\mathrm{Hg}$ pollution over a specific developing region. 


\subsection{Recommendations and uncertainties}

Aiming to improve economic competitiveness, China proposed the ambitious Made in China 2025 strategy to promote the development of high-end manufacturing sectors. ${ }^{51}$ Increasing consumption of products from high-end manufacturing sectors (e.g., equipment, machinery, and vehicles) which require substantial Hg-intensive upstream inputs is predicted to increase $\mathrm{Hg}$ emissions in the future. ${ }^{18}$ In addition, China has focused on building and developing urban agglomerations since the $11^{\text {th }}$ Five-Year Plan. ${ }^{52,53}$ This rapid development of urban agglomerations calls for more and more consumption and imports. Such increased consumption and imports suggests that more and more $\mathrm{Hg}$ emissions will be exported from coastal developed urban agglomerations to inland developing regions in the future. Above all, if no measures were taken, Hg-related health risks would be aggravated. Reflecting both interprovincial trade and atmospheric movement, inland developing regions would be exposed to more Hg-related health risks than coastal developed regions. To control these aspects of $\mathrm{Hg}$ pollution, both end-of-pipe $\mathrm{Hg}$ controls and demand-side $\mathrm{Hg}$ controls are essential for China, especially the encouragement of interprovincial collaboration on demand-side Hg controls.

Our emission and model results are subject to uncertainties from a variety of sources. The calculations of consumption-based emissions, including trade-induced emissions are subject to errors inherent in the production-based emissions and the input-output table. A detailed error analysis for the consumption-based emissions is presented in SI S6. We calculate an overall uncertainty of $[-27 \%, 32 \%]$ for the 
435

436

consumption-based emissions, including the trade-induced emissions in our study.

The atmospheric model results are subject to errors in emission inputs, as well as the model representations of tropospheric chemical processes, especially $\mathrm{Hg}$ chemistry, and meteorological processes. The model uncertainties are difficult to quantify and are likely on the order of $30 \%{ }^{54}$ Meanwhile, it is computationally prohibitive to perform Monte Carlo simulations or sensitivity analyses that integrate all errors associated with emissions, the input-output model and the chemical transport model. A common practice to quantify model uncertainties is through an evaluation of the model performance against observations. We outline such an evaluation in SI S4. In Figures $2-5$, we present our results as a percentage contribution, in which case, the associated uncertainties may be reduced. The uncertainties in atmospheric $\mathrm{Hg}$ deposition flux from various simulations may largely offset each other, when their differences are normalized through calculation of a percentage. More field measurements on production emission processes and atmospheric chemical processes involving $\mathrm{Hg}$ in the future would reduce uncertainties in emission inventories and chemical transport models, respectively. This would eventually enhance the accuracy of results in this study.

Moreover, we use the MRIO database developed by Liu et al., ${ }^{39}$ to quantify $\mathrm{Hg}$ emissions embodied in China's interregional trade. This makes it easy to compare our results to existing studies ${ }^{19,34,55,56}$ mostly based on the MRIO databases of Liu et al. ${ }^{39}$ It is worth noting that there are also many other MRIO databases for China, including the databases of Shi and Zhang, ${ }^{57}$ Zhang and $\mathrm{Qi}^{58}$ and Wang et al. ${ }^{59,60}$ It would be 
457

458

459

460

461

462

463

464

465

466

467

468

469

470

471

472

473

474

475

476

477

478

important to compare and harmonize these MRIO databases in future studies.

In general, revealing embodied $\mathrm{Hg}$ deposition within economic supply chains

from a consumer perspective helps uncover the underlying trans-boundary drivers of regional $\mathrm{Hg}$ pollution and assess the effects of proposed demand-side measures on the mitigation of $\mathrm{Hg}$ pollution. Although this study only considers China, the framework developed in this study could be applied to evaluate international collaboration on the demand-side $\mathrm{Hg}$ controls between developed and developing countries. Finally, this framework could be applied to other developing countries with large differences in domestic regional development, such as the BRICS countries.

\section{Author Information}

\section{Corresponding Authors}

*(J.S.) Phone: +86-21-54341198; e-mail: jshu@geo.ecnu.edu.cn.

*(X.W.) Phone: +86-10-62759190; e-mail: xjwang@urban.pku.edu.cn.

\section{Acknowledgments}

The authors would like to thank the editor and anonymous reviewers for their thoughtful comments. This study was funded by the National Natural Science Foundation of China $(41701589,41271055,41630748,41571130010,41471403)$, and China Postdoctoral Science Foundation Grant (2017M611492). Sai Liang thanks the financial support of the Interdiscipline Research Funds of Beijing Normal University and the Start-up Funds of Beijing Normal University (312232104). All map images 
479

480

481

482

483

484

485

are plotted by GAMAP (Global Atmospheric Model Analysis Package, Version 2.17;

http://acmg.seas.harvard.edu/gamap/). The computation was supported by the High Performance Computer Center of East China Normal University.

\section{Supporting Information}

The Supporting Information provides additional text, tables, and figures supporting the main text. 


\section{References}

(1) Streets, D. G.; Devane, M. K.; Lu, Z.; Bond, T. C.; Sunderland, E. M.; Jacob, D. J. All-time releases of mercury to the atmosphere from human activities. Environ. Sci. Technol. 2011, 45 (24), 10485-10491.

(2) Horowitz, H. M.; Jacob, D. J.; Amos, H. M.; Streets, D. G.; Sunderland, E. M. Historical mercury releases from commercial products: Global environmental implications. Environ. Sci. Technol. 2014, 48 (17), 10242-10250.

(3) Lindberg, S.; Bullock, R.; Ebinghaus, R.; Engstrom, D.; Feng, X.; Fitzgerald, W.;

Pirrone, N.; Prestbo, E.; Seigneur, C. A synthesis of progress and uncertainties in attributing the sources of mercury in deposition. Ambio 2007, 36 (1), 19-33.

(4) Corbitt, E. S.; Jacob, D. J.; Holmes, C. D.; Streets, D. G.; Sunderland, E. M. Global source-receptor relationships for mercury deposition under present-day and 2050 emissions scenarios. Environ. Sci. Technol. 2011, 45 (24), 10477-10484.

(5) Mergler, D.; Anderson, H. A.; Chan, L. H. M.; Mahaffey, K. R.; Murray, M.; Sakamoto, M.; Stern, A. H. Methylmercury exposure and health effects in humans: A worldwide concern. Ambio 2007, 36 (1), 3-11.

(6) Mahaffey, K. R.; Sunderland, E. M.; Chan, H. M.; Choi, A. L.; Grandjean, P.; Mariën, K.; Oken, E.; Sakamoto, M.; Schoeny, R.; Weihe, P.; Yan, C.-H.; Yasutake, A. Balancing the benefits of n-3 polyunsaturated fatty acids and the risks of methylmercury exposure from fish consumption. Nut. Rev. 2011, 69 (9), 493-508.

(7) Grandjean, P.; Satoh, H.; Murata, K.; Eto, K. Adverse effects of methylmercury: Environmental health research implications. Environ. Health Persp. 2010, 118 (8), 1137-1145.

(8) Karagas, M. R.; Choi, A. L.; Oken, E.; Horvat, M.; Schoeny, R.; Kamai, E.; Cowell, W.; Grandjean, P.; Korrick, S. Evidence on the human health effects of low-level methylmercury exposure. Environ. Health Persp. 2012, 120 (6), 799-806.

(9) Harris, R. C.; Rudd, J. W.; Amyot, M.; Babiarz, C. L.; Beaty, K. G.; Blanchfield, 
513 P. J.; Bodaly, R. A.; Branfireun, B. A.; Gilmour, C. C.; Graydon, J. A. 514 Whole-ecosystem study shows rapid fish-mercury response to changes in mercury 515 deposition. Proc. Natl. Acad. Sci. U. S. A. 2007, 104, (42), 16586-16591.

516 (10) Vijayaraghavan, K.; Levin, L.; Parker, L.; Yarwood, G.; Streets, D. Response of 517 fish tissue mercury in a freshwater lake to local, regional, and global changes in 518 mercury emissions. Environ. Toxicol. Chem. 2014, 33 (6), 1238.

519 (11) United Nations Environment Programme (UNEP). Minamata Convention on 520 Mercury http://www.mercuryconvention.org.

521 (12) Arctic Monitoring and Assessment Programme and United Nations Environment 522 Programme (AMAP/UNEP). Technical Background Report for the Global Mercury 523 Assessment; AMAP/UNEP: Geneva, Switzerland, 2013.

524 (13) Ministry of environmental Protection (MEP). Notice on the guidance opinions of 525 promoting the atmospheric pollution defense spreading work to improve regional air 526 quality; MEP: Beijing, China, 2010.

527 (14) Ministry of Environmental Protection (MEP). Notice about related issues of 528 support policy of ultra-low emission electricity price of coal-fired power plant; MEP: 529 Beijing, China, 2015.

530 (15) Ministry of Industry and Information Technology (MIIT). Specification 531 conditions on lead and zinc industry; MIIT: Beijing, China, 2014.

532 (16) Wu, Q.; Wang, S.; Li, G.; Liang, S.; Lin, C. J.; Wang, Y.; Cai, S.; Liu, K.; Hao, J. 533 Temporal trend and spatial distribution of speciated atmospheric mercury emissions in 534 China during 1978-2014. Environ. Sci. Technol. 2016, 50 (24), 13428-13435.

535 (17) Ministry of Environmental Protection (MEP). Technical policy about mercury 536 pollution control; MEP: Beijing, China, 2013.

537 (18) Hui, M.; Wu, Q.; Wang, S.; Liang, S.; Zhang, L.; Wang, F.; Lenzen, M.; Wang, Y.; 538 Xu, L.; Lin, Z. Mercury flows in China and global drivers. Environ. Sci. Technol. $539 \quad \mathbf{2 0 1 7}, 51(1), 222-231$. 
540 (19) Liang, S.; Chao, Z.; Wang, Y.; Ming, X.; Liu, W. Virtual atmospheric mercury 541 emission network in China. Environ. Sci. Technol. 2014, 48 (5), 2807-2815.

542 (20) Guo, J. E.; Zhang, Z.; Meng, L. China's provincial $\mathrm{CO}_{2}$ emissions embodied in 543 international and interprovincial trade. Energy Policy 2012, 42 (C), 486-497.

544 (21) Jiang, W. Q.; Li, J. S.; Chen, G. Q.; Yang, Q.; Alsaedi, A.; Ahmad, B.; Hayat, T. 545 Mercury emissions embodied in Beijing economy. J. Clean. Prod. 2016, 129, 134$546 \quad 142$.

547 (22) Li, J. S.; Chen, G. Q.; Chen, B.; Yang, Q.; Wei, W. D.; Wang, P.; Dong, K. Q.; 548 Chen, H. P. The impact of trade on fuel-related mercury emissions in Beijing549 evidence from three-scale input-output analysis. Renew. Sust. Energ. Rev. 2017, 75, $550 \quad 742-752$.

551 (23) Liang, S.; Xu, M.; Liu, Z.; Suh, S.; Zhang, T. Socioeconomic drivers of mercury 552 emissions in China from 1992 to 2007. Environ. Sci. Technol. 2013, 47 (7), 3234 5533240.

554 555

556

557

558

559

560

561

562

563

564

565

566

(24) Li, J. S.; Chen, B.; Chen, G. Q.; Wei, W. D.; Wang, X. B.; Ge, J. P.; Dong, K. Q.;

Xia, H. H.; Xia, X. H. Tracking mercury emission flows in the global supply chains: A multi-regional input-output analysis. J. Clean. Prod. 2017, 140, 1470-1492.

(25) National Energy Statistical Agency of China (NESA). China Energy Statistical Yearbook; NESA: Beijing, China, 2011.

(26) National Statistical Bureau of China (NSB). China Statistical Yearbook; NSB: Beijing, China, 2011.

(27) Nonferrous Metal Industry Association of China (NMIA). Yearbook of Nonferrous Metals Industry of China; NMIA: Beijing, China, 2011.

(28) China Iron and Steel Industry Association (CISIA). China Steel Yearbook; CISIA: Beijing, China, 2011.

(29) Chen, S. China mining yearbook; Seismological Press: Beijing, China, 2011.

(30) Editoral Board of China Electric Power Yearbook. China Electric Power 
Yearbook; China Electric Power Press: Beijing, China, 2011.

568 (31) U.S. Geological Survey (USGS). Minerals information http://

569

570

571

572

573

574

575

576

577

578

579

580

581

582

583

584

585

586

587

588

589

590

591

592

593

minerals.usgs.gov/minerals/pubs/commodity/.

(32) China Cement Network. Maps for cement plants http://hy.ccement.com/map/.

(33) Center for International Earth Science Information Network (CIESIN), Columbia University. Gridded Population of the World (GPW), Version 3 http://beta.sedac.ciesin.columbia.edu/gpw/index.jsp.

(34) Li, Y.; Meng, J.; Liu, J.; Xu, Y.; Guan, D.; Wei, T.; Huang, Y.; Tao, S. Inter-provincial reliance for improving air quality in China: A case study on black carbon aerosol. Environ. Sci. Technol. 2016, 50 (7), 4118-4126.

(35) Lin, J.; Tong, D.; Davis, S.; Ni, R.; Tan, X.; Pan, D.; Zhao, H.; Lu, Z.; Streets, D.; Feng, T.; Zhang, Q.; Yan, Y.; Hu, Y.; Li, J.; Liu, Z.; Jiang, X.; Geng, G.; He, K.; Huang, Y.; Guan, D. Global climate forcing of aerosols embodied in international trade. Nat. Geosci. 2016, 9 (10), 790-794.

(36) Liang, S.; Wang, Y.; Cinnirella, S.; Pirrone, N. Atmospheric mercury footprints of nations. Environ. Sci. Technol. 2015, 49 (6), 3566-3574.

(37) Lenzen, M.; Moran, D.; Kanemoto, K.; Foran, B.; Lobefaro, L.; Geschke, A. International trade drives biodiversity threats in developing nations. Nature 2012, 486 (7401), 109-112.

(38) Davis, S. J.; Caldeira, K. Consumption-based accounting of $\mathrm{CO}_{2}$ emissions. Proc. Natl. Acad. Sci. U. S. A. 2010, 107 (12), 5687.

(39) Liu, W. D.; Tang, Z. P.; Chen, J.; Yang, B. China's interregional input-output table for 30 regions in 2010 (in Chinese); China Statistics Press: Beijing, China, 2014. (40) Peters, G. P.; Weber, C. L.; Guan, D.; Hubacek, K. China's growing $\mathrm{CO}_{2}$ emissions-a race between increasing consumption and efficiency gains. Environ. Sci. Technol. 2007, 41 (17), 5939-5944.

(42) Miller, R. E.; Blair, P. D. Input-output analysis: foundations and extensions, 2nd 
ed; Cambridge University Press: Cambridge, UK, 2009.

(43) Weber, C. L.; Peters, G. P.; Guan, D.; Hubacek, K. The contribution of Chinese exports to climate change. Energy Policy 2008, 36 (9), 3572-3577.

(43) Holmes, C. D.; Jacob, D. J.; Corbitt, E. S.; Mao, J.; Yang, X.; Talbot, R.; Slemr, F. Global atmospheric model for mercury including oxidation by bromine atoms. Atmos. Chem. Phys. 2010, 10 (24), 12037-12057.

(44) Soerensen, A. L.; Sunderland, E. M.; Holmes, C. D.; Jacob, D. J.; Yantosca, R. M.; Skov, H.; Christensen, J. H.; Strode, S. A.; Mason, R. P. An improved global model for air-sea exchange of mercury: High concentrations over the North Atlantic. Environ. Sci. Technol. 2010, 44 (22), 8574-8580.

(45) Zhang, Y.; Jaeglé, L.; van Donkelaar, A.; Martin, R. V.; Holmes, C. D.; Amos, H. M.; Wang, Q.; Talbot, R.; Artz, R.; Brooks, S.; Luke, W.; Holsen, T. M.; Felton, D.; Miller, E. K.; Perry, K. D.; Schmeltz, D.; Steffen, A.; Tordon, R.; Weiss-Penzias, P.; Zsolway, R. Nested-grid simulation of mercury over North America. Atmos. Chem. Phys. 2012, 12 (14), 6095-6111.

(46) Wang, L.; Wang, S.; Zhang, L.; Wang, Y.; Zhang, Y.; Nielsen, C.; McElroy, M. B.; Hao, J. Source apportionment of atmospheric mercury pollution in China using the GEOS-Chem model. Environ. pollut. 2014, 190, 166-175.

(47) Amos, H. M.; Jacob, D. J.; Holmes, C. D.; Fisher, J. A.; Wang, Q.; Yantosca, R. M.; Corbitt, E. S.; Galarneau, E.; Rutter, A. P.; Gustin, M. S.; Steffen, A.; Schauer, J. J.; Graydon, J. A.; Louis, V. L. S.; Talbot, R. W.; Edgerton, E. S.; Zhang, Y.; Sunderland, E. M. Gas-particle partitioning of atmospheric $\mathrm{Hg}(\mathrm{II})$ and its effect on global mercury deposition. Atmos. Chem. Phys. 2012, 12 (1), 591-603.

(48) Wang, H.; Rasch, P. J.; Easter, R. C.; Singh, B.; Zhang, R.; Ma, P. L.; Qian, Y.; Ghan, S. J.; Beagley, N. Using an explicit emission tagging method in global modeling of source-receptor relationships for black carbon in the Arctic: Variations, sources and transport pathways. J. Geophys. Res. Atmos. 2014, 119 (22), 1288812909. 
(49) Rasch, P. J.; Barth, M. C.; Kiehl, J. T.; Schwartz, S. E.; Benkovitz, C. M. A description of the global sulfur cycle and its controlling processes in the National Center for Atmospheric Research Community Climate Model, Version 3. J. Geophys. Res. Atmos. 2000, 105 (D1), 1367-1385.

(50) Ministry of Environmental Protection (MEP). "Twelfth Five-year” plan for the comprehensive prevention and control of heavy metal pollution; MEP: Beijing, China, 2011.

(51) State Council of the People's Republic of China (SC). Notice on printing and $\begin{array}{llll}\text { distributing } & \text { Made } & \text { in } & \text { China }\end{array}$ http://www.gov.cn/zhengce/content/2015-05/19/content_9784.htm.

(52) State Council of the People's Republic of China (SC). The $11^{\text {th }}$ five-year plan (2006-2010) http://www.gov.cn/index.htm.

(53) State Council of the People's Republic of China (SC). National new urbanization plan (2014-2020) http://www.gov.cn/zhengce/2014-03/16/content_2640075.htm.

(54) Lin, J. T.; Liu, Z.; Zhang, Q.; Liu, H. Modeling uncertainties for tropospheric nitrogen dioxide columns affecting satellite-based inverse modeling of nitrogen oxides emissions. Atmos. Chem. Phys. 2012, 12 (24), 12255-12275.

(55) Feng, K.; Davis, S. J.; Sun, L.; Li, X.; Guan, D.; Liu, W.; Liu, Z.; Hubacek, K. Outsourcing CO2 within China. Proc. Natl. Acad. Sci. U. S. A. 2013, 110 (28), 1165411659.

(56) Wang, H.; Zhang, Y.; Zhao, H.; Lu, X.; Zhang, Y.; Zhu, W.; Nielsen, C. P.; Li, X.; Zhang, Q.; Bi, J. Trade-driven relocation of air pollution and health impacts in China. Nat. Commun. 2017, 8 (1), 738.

(57) Shi, J.; Zhang, Z. Inter-province input-output model and interregional economic linkage in China (in Chinese); Science Press: Beijing, China, 2012.

(58) Zhang, Y.; Qi, S. China multi-regional input-output models(in Chinese); China Statistics Press: Beijing, China, 2012. 
649 (59) Wang, Y.; Geschke, A.; Lenzen, M. Constructing a time series of nested 650 multiregion input-output tables. Int. Reg. Sci. Rev. 2017, 40 (5), 476-499.

651 (60) Wang, Y. An industrial ecology virtual framework for policy making in China. 652 Econ. Syst. Res. 2017, 29 (2), 252-274.

$-30-$ 


\section{Figure Captions}

Figure 1. Production-based and consumption-based $\mathrm{Hg}$ emissions (A), emissions embodied in exports (EEE) and emissions embodied in imports (EEI) (B), and net emissions transfer (C) for 30 Chinese provinces.

Figure 2. Contributions from China's total anthropogenic sources (A), total trade (B), interprovincial trade (C), and international export (D) to atmospheric $\mathrm{Hg}$ deposition over China.

Figure 3. Spatial redistribution of atmospheric $\mathrm{Hg}$ deposition by trade over China, including the spatial redistribution of atmospheric $\mathrm{Hg}$ deposition (A), the deposition variation over each provincial or marine receptor due to the trade activities of each province (B), and the contributions of the provincial trade activities to total national deposition (C). The abbreviations are HL, Heilongjiang; JL, Jilin; LN, Liaoning; BJ, Beijing; TJ, Tianjin; HE, Hebei; SX, Shanxi; SD, Shandong; HA, Henan; HB, Hubei; HN, Hunan; AH, Anhui; JX, Jiangxi; SH, Shanghai; JS, Jiangsu; ZJ, Zhejiang; FJ, Fujian; GD, Guangdong; HI, Hainan; GX, Guangxi; CQ, Chongqing; SC, Sichuan; GZ, Guizhou; YN, Yunnan; NM, Inner Mongolia; SN, Shaanxi; GS, Gansu; QH, Qinghai; NX, Ningxia; XJ, Xinjiang; FN, foreign countries; Bs, Bohai Sea; Ys, Yellow Sea; Es, East China Sea; Ss, South China Sea.

Figure 4. Source-receptor relationship between provincial final consumption and on-site emission (A) and atmospheric Hg deposition (B). "Source" denotes the unity final consumption of each province and foreign countries. "Receptor" denotes percentage variation of on-site emission or atmospheric deposition over each receptor. The abbreviations are the same as Figure 3.

Figure 5. Impact of the hypothetical substitution of emission intensity from developed provinces to their trade partners on atmospheric $\mathrm{Hg}$ deposition over China. 
683 The developed provinces include Beijing (a), Tianjin (b), Shanghai (c), Jiangsu (d), 684 Zhejiang (e), and Guangdong (f).

$-32-$ 


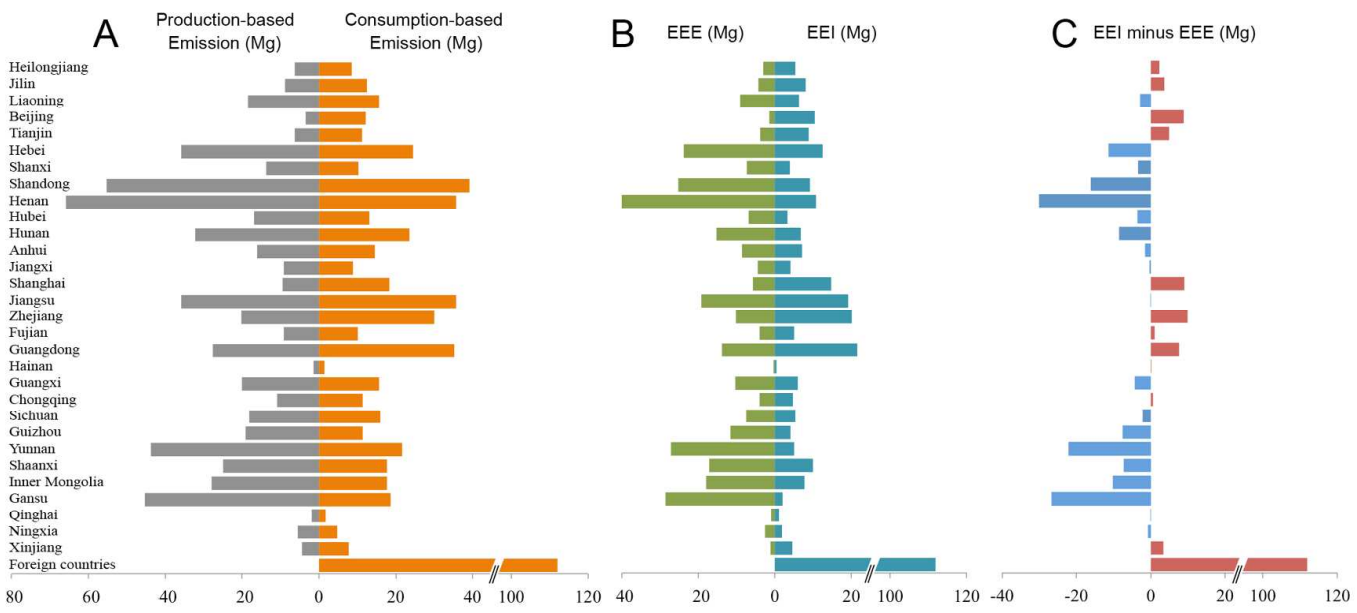

Figure 1. Production-based and consumption-based $\mathrm{Hg}$ emissions (A), emissions embodied in exports (EEE) and emissions embodied in imports (EEI) (B), and net emissions transfer (C) for 30 Chinese provinces. 
A) Total anthropogenic sources

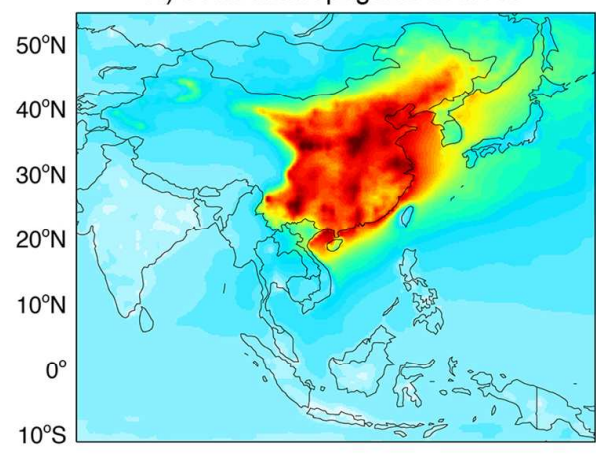

C) Interprovincial trade

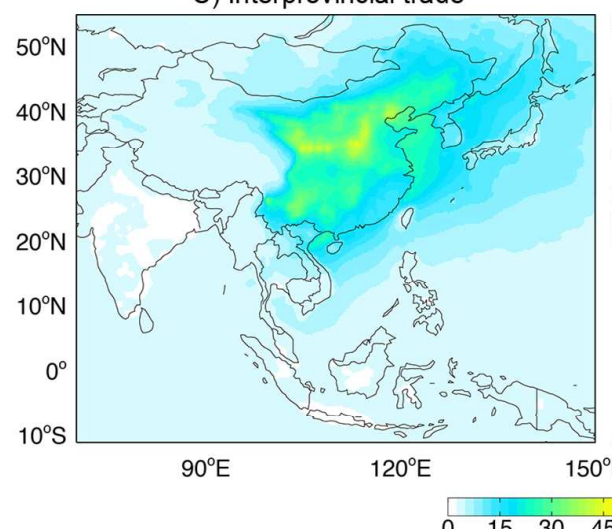

B) Total trade

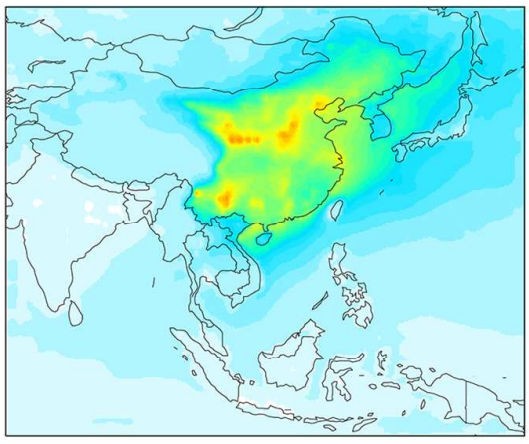

D) International export

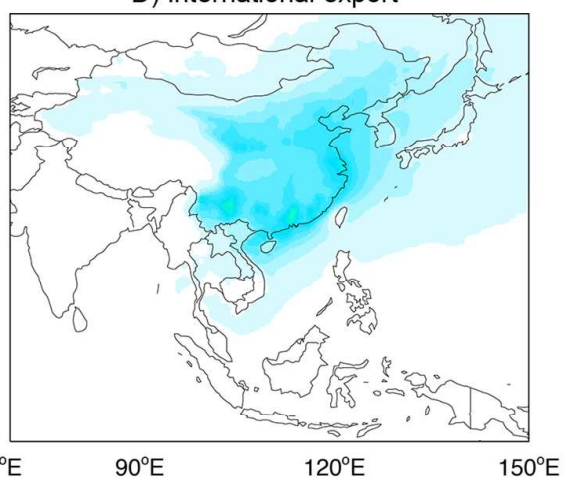

690 Figure 2. Contributions from China's total anthropogenic sources (A), total trade (B),

691 interprovincial trade (C), and international export (D) to atmospheric $\mathrm{Hg}$ deposition over China. 

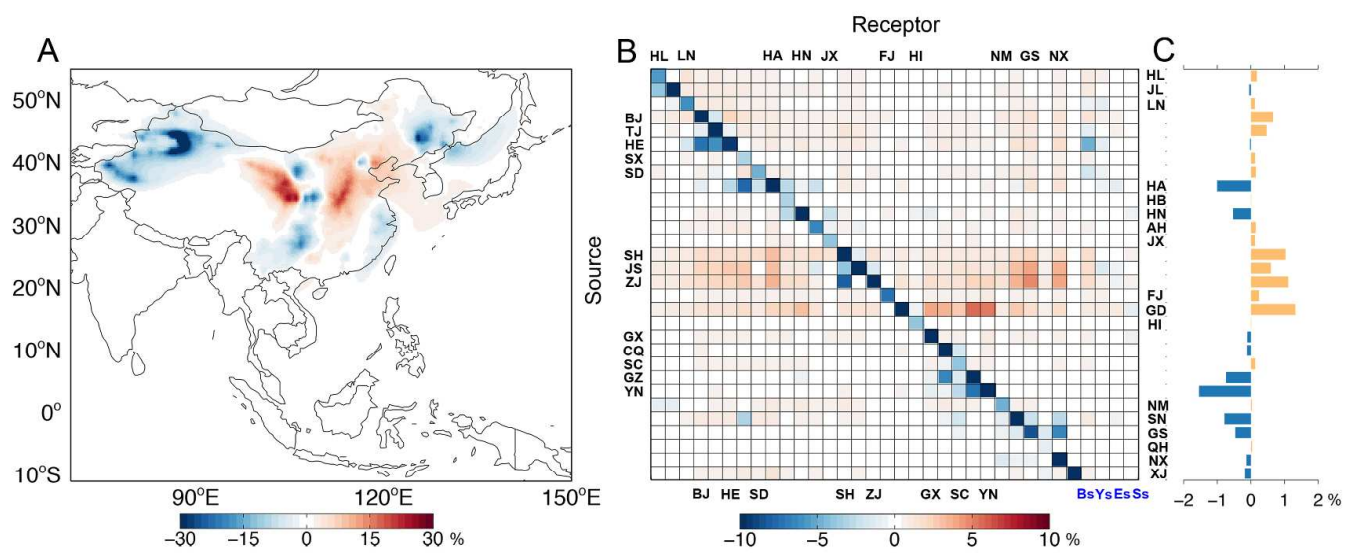

693

694

695

696

697

698

699

700

701

702

703

704

Figure 3. Spatial redistribution of atmospheric $\mathrm{Hg}$ deposition by trade over China, including the spatial redistribution of atmospheric $\mathrm{Hg}$ deposition (A), the deposition variation over each provincial or marine receptor due to the trade activities of each province (B), and the contributions of the provincial trade activities to total national deposition (C). The abbreviations are HL, Heilongjiang; JL, Jilin; LN, Liaoning; BJ, Beijing; TJ, Tianjin; HE, Hebei; SX, Shanxi; SD, Shandong; HA, Henan; HB, Hubei; HN, Hunan; AH, Anhui; JX, Jiangxi; SH, Shanghai; JS, Jiangsu; ZJ, Zhejiang; FJ, Fujian; GD, Guangdong; HI, Hainan; GX, Guangxi; CQ, Chongqing; SC, Sichuan; GZ, Guizhou; YN, Yunnan; NM, Inner Mongolia; SN, Shaanxi; GS, Gansu; QH, Qinghai; NX, Ningxia; XJ, Xinjiang; FN, foreign countries; Bs, Bohai Sea; Ys, Yellow Sea; Es, East China Sea; Ss, South China Sea. 


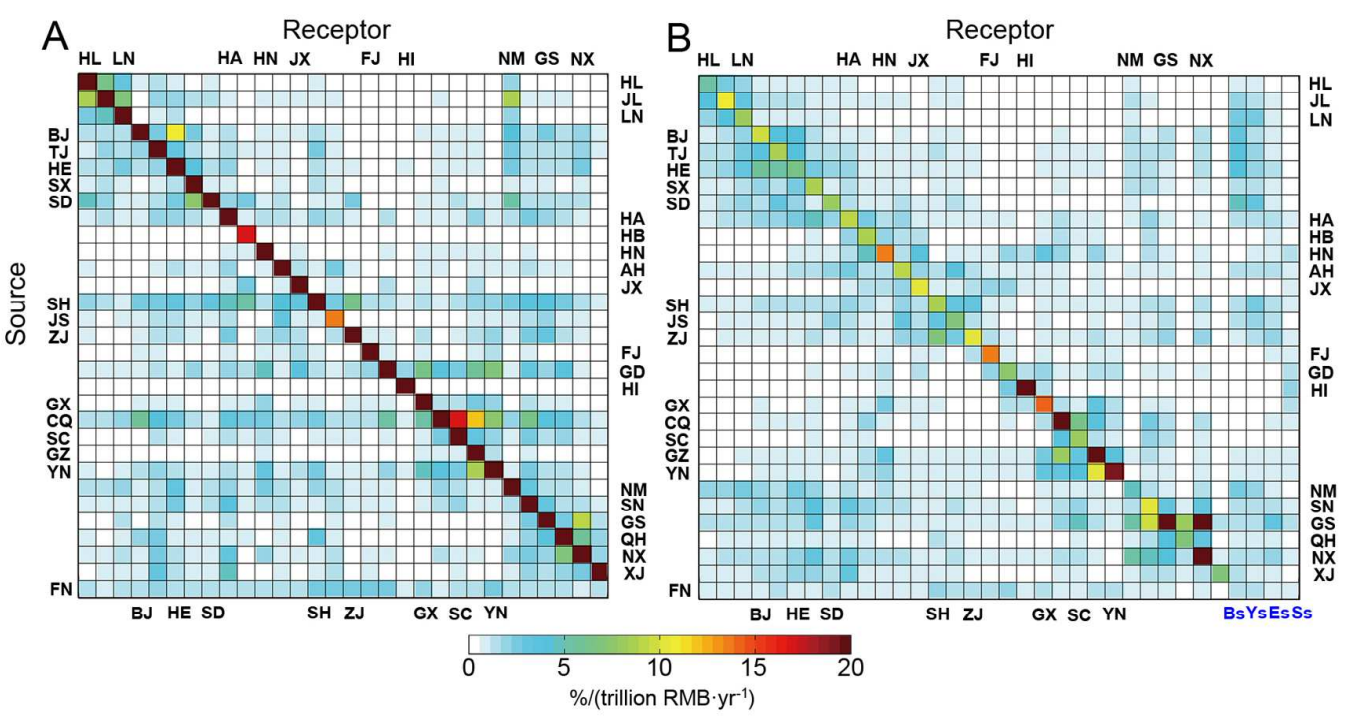

Figure 4. Source-receptor relationship between provincial final consumption and on-site emission (A) and atmospheric Hg deposition (B). "Source" denotes the unity

708 final consumption of each province and foreign countries. "Receptor" denotes 709 percentage variation of on-site emission or atmospheric deposition over each receptor.

710 The abbreviations are the same as Figure 3. 
a) Beijing

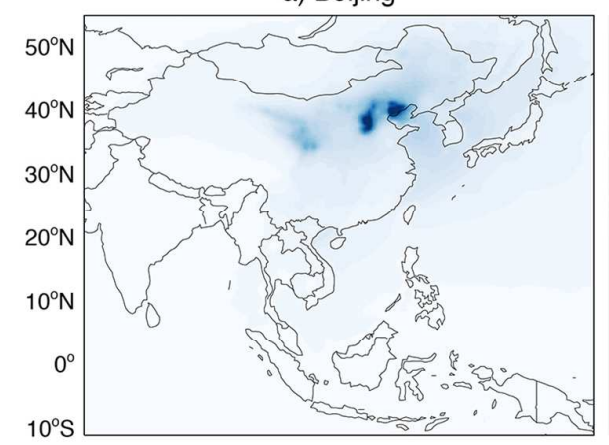

c) Shanghai

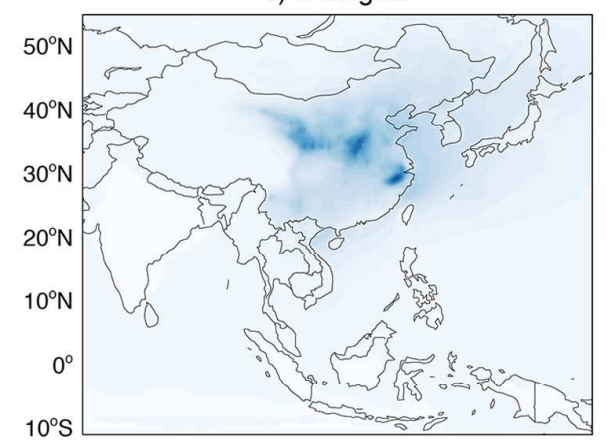

e) Zhejiang

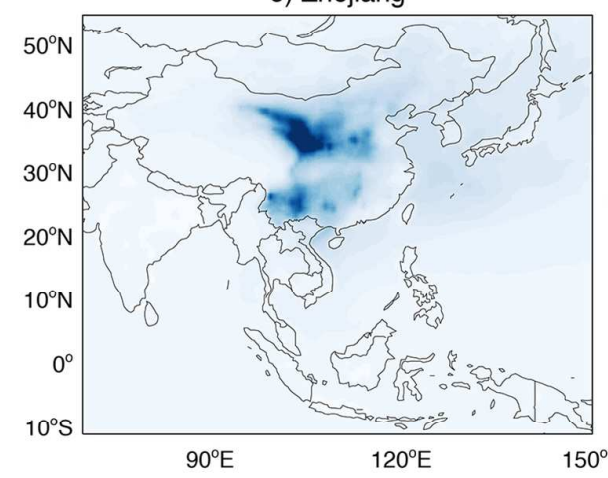

b) Tianjin

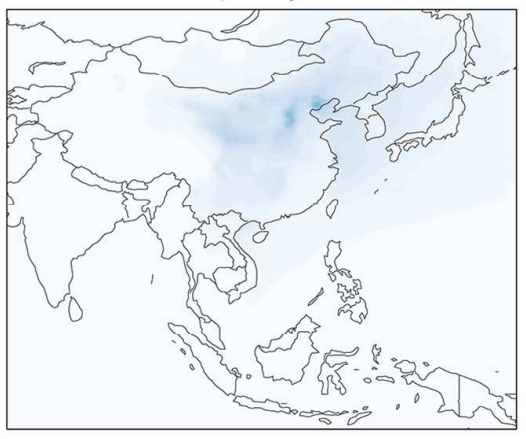

d) Jiangsu

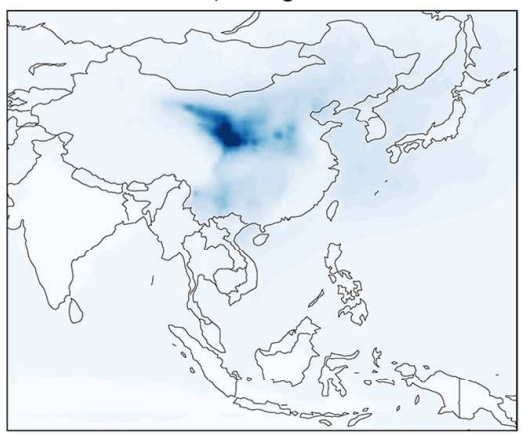

f) Guangdong

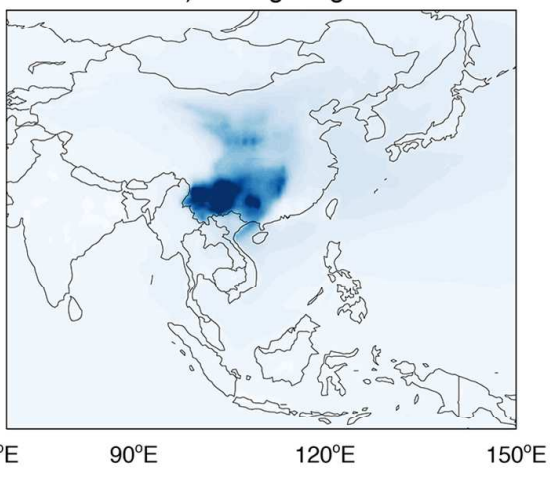

712 Figure 5. Impact of the hypothetical substitution of emission intensity from

713 developed provinces to their trade partners on atmospheric Hg deposition over China.

714 The developed provinces include Beijing (a), Tianjin (b), Shanghai (c), Jiangsu (d), 


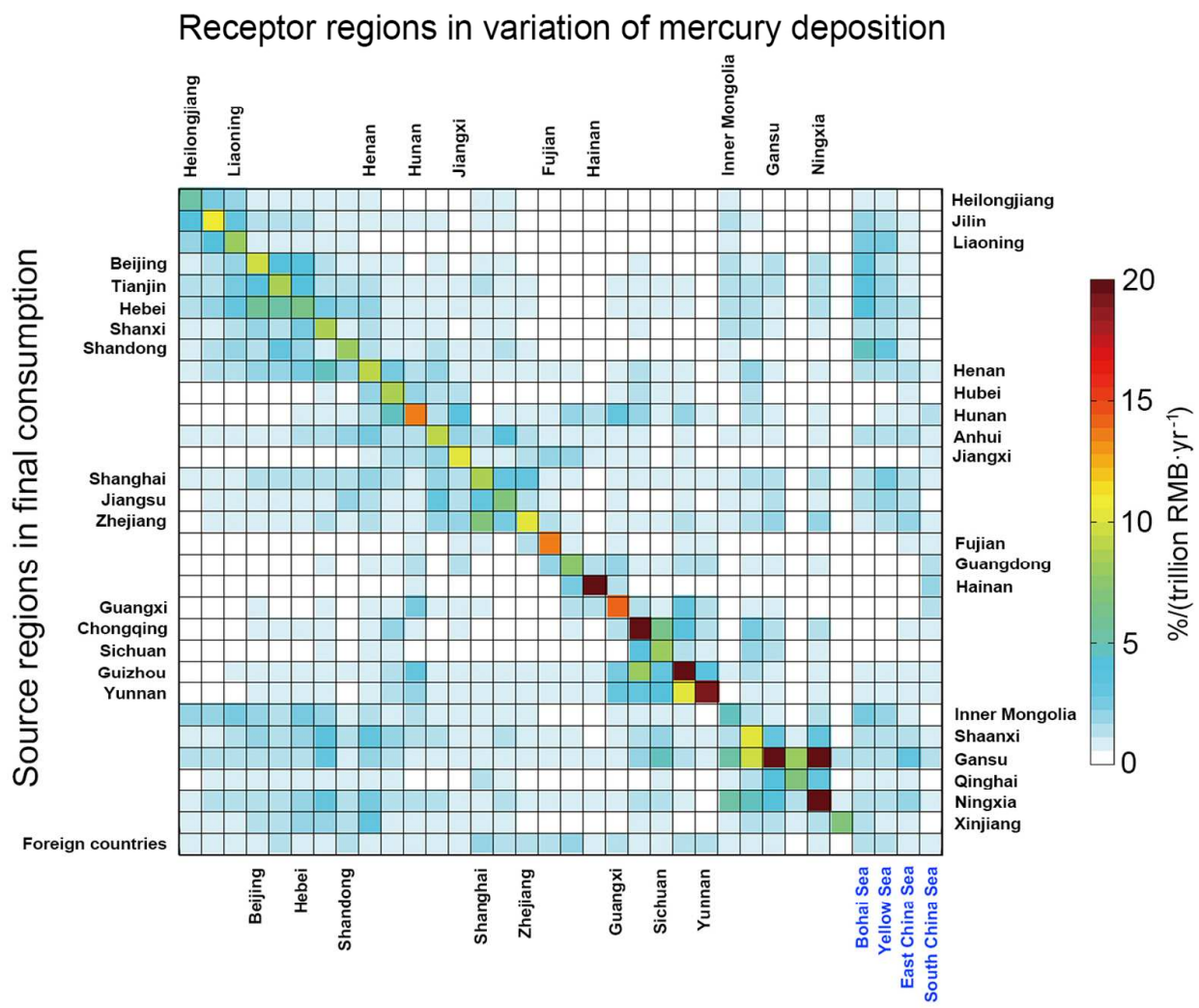

